\title{
Visando a modernidade arco e flecha e a modernização do Japão
}

Allen Guttman*

Resumo: O texto analisa a modernização a sociedade japonesa no que se refere à rápida aceitação de esportes modernos oriundos da Europa e da América do Norte. Focalizando a prática do arco e flecha japonês (kyûjutsu) e identificando-a como uma atividade não européia, o argumento central é o de que a rápida aceitação dos esportes modernos pela sociedade japonesa pode ser meIhor entendida quando verificamos que algumas das principais características deste esporte (a racionalização, a quantificação e a busca do recorde), já estavam presentes na sociedade japonesa, antes do período da reforma daquele país. Buscando mostrar como as características do esporte moderno são identificáveis na prática do arco e flecha japonês, conclui-se que, estando as sementes da modernidade presentes no Japão antes do próprio processo de modernização, torna-se mais fácil a compreensão deste acontecimento histórico.

Palavras-chave: História, Cultura, Esporte, Modernidade.

O Japão foi a primeira sociedade asiática a cruzar a barreira cultural que separa as sociedades tradicionais das modernas. Um aspecto dessa transição para a modernidade foi a rápida difusão durante o século XIX e início do século XX na sociedade japonesa do beisebol, futebol, futebol americano, golfe, tênis e outros esportes modernos inventados na Europa e América do Norte. Uma razão para essa rápida difusão, para essa imediata aceitação de novos esportes, pode ter sido o fato de que algumas características podem não ter sido de todo novas. Não estou insinuando que os aristocratas japoneses dos períodos Hein e Kamakura tenham jogado beisebol ou futebol, mas estou intrigado com alguns aspectos do arco e flecha japonês.

Já no século XVII, o arco e flecha japonês possuía várias das mais importantes características do esporte moderno - sendo que uma dessas características pode ser traçada desde o século XIII. Não quero sugerir que a modernização da sociedade japonesa tenha de qualquer forma sido "causada" pelo esporte do arco e flecha. Longe

* Doutor em Estudos Americanos. Professor da Amherst College, Estados Unidos.

Movimento, Porto Alegre, v. 10, n. 3, p.9-21, setembro/dezembro de 2004 
disso. Eu quero dizer, entretanto, que o arco e flecha japonês kyûjutsu - é uma pista para a predisposição na cultura japonesa que tornou os japoneses especialmente receptivos às influências modernas do Ocidente. ${ }^{1}$ Devo acrescentar que os historiadores foram de certa forma cegos aos aspectos modernos do arco e flecha moderno por terem sido ofuscados pelo aspecto religioso do arco e flecha. No seu livro, "Zen in the Art of Archery", o filósofo alemão Eugen Herrigel conta uma boa história, mas não a única que pode ser contada sobre o arco e flecha japonês. ${ }^{2}$

Deixe-me apresentar muito brevemente, sem a evidência que já apresentei, três das características do esporte moderno (que são em geral características da sociedade moderna). O esporte moderno apresenta um alto nível do que o sociólogo alemão Max Weber chamou de zweckationalität - "racionalismo instrumental". Abstração e padronização são duas formas dessa racionalização. Um dos meus exemplos favoritos é o cavalo com alças da ginástica. Originalmente, claro, o cavalo era um cavalo real, montado por cavaleiros de verdade que então demonstravam suas habilidades eqüestres como ainda fazem hoje em esportes como a equitação. Agora, como todos sabem - muitos para sua grande tristeza - alguns cavalos são melhores que os outros, mais fortes, mais rápidos, mais facilmente domados, o que confere uma clara vantagem sobre seus afortunados montadores. A padronização iguala a competição. O garanhão eqüestre tornou-se o cavalo de madeira do ginasta. No século XIX ele ainda parecia razoavelmente eqüino. Além das suas quatro patas de madeira, o dispositivo tinha uma cabeça de madeira e uma cauda de crinas, nenhuma das quais sobreviventes ao impulso racionalizante. A idéia dessa nem tão platônica versão de um cavalo era a de que se tratava de um equipamento padronizado que não desse vantagem a nenhum dos competidores. Um triunfo da

1 Richard Mandell chegou à mesma conclusão: "algumas características especiais do esporte japonês também sugerem que alguns pré-requisitos para a modernização estavam presentes no Japão muito antes da sua surpreendente modernização, no final do século XIX"; ver Sport: A Cultural History. New York: Columbia University Press, 1984, p. 100. Em uma dissertação redigida dois anos antes, sugiro o mesmo; ver "The Sociological Imaginationand the Imaginative Sociologist," Sport and the Sociological Imagination, ed. Nancy Theberge e Peter Donnelly. Fort Worth: Texas Christian University Press, 1984. p. 4-20. Mandell e eu somos amigos íntimos e discutimos a história do esporte em incontáveis ocasiões. Não posso dizer qual de nós dois foi o primeiro a ficar intrigado pela possibilidade do que podemos chamar de modernidade antecipada do arco e flecha japonês.

2 Eugen Herrigel, Zen in der Kunst des Bogenschiessens. Tübingen: Otto-Wilhelm Barth, 1975.

3 Max Weber, Wirtschaft und Gesellschaft, ed. Johannes Winckelmann, 2 vols. Cologne: Kiepenhauer \& Witsch, 1964.

Movimento, Porto Alegre, v. 10, n. 3, p. 9-21, setembro/dezembro de 2004 
racionalidade lúdica e um esplêndido exemplo do que George Vigarello chama de "deréalisation". ${ }^{4}$

Uma segunda e mais marcante característica do esporte moderno é o impulso de quantificar as conquistas. Essa característica merece ser melhor explicada. Hoje vivemos em um mundo de números. No atletismo medimos as distâncias até o centímetro, e o tempo até os centésimos de segundo. Em Munique, em 1972, os organizadores alemães dos Jogos Olímpicos mediram os tempos dos nadadores até os milésimos de segundo, o que significou pelo menos um caso em que o ganhador da medalha de prata na verdade nadou mais rápido que o ganhador da medalha de ouro. (A explicação é a de que a diferença espacial, ou seja, a diferença de distância entre as raias dos nadadores era muito maior do que a diferença temporal).

Quando os Jogos Olímpicos foram restaurados, em 1896, um observador americano comentou que as competições de ginástica não eram particularmente populares porque não eram passíveis de medidas precisas. ${ }^{5}$ Hoje, medimos os escores da ginástica até três casas decimais. O total de Nadia Comanecci em 1976, nos Jogos de Montreal foi de 79.275, o que significa - nós acreditamos - que a sua performance deve ter sido melhor do que a de Ludmilla Tourisheva nos Jogos de Munique quatro anos antes. Afinal de contas, ela marcou meros 77.025 pontos.

Nós vivemos em um mundo de números, mas os gregos não viviam. Apesar de Pitágoras, Arquimedes, Euclídes e outros terem feito grande contribuições para a matemática, a civilização grega não era obcecada pela necessidade de quantificar. Para eles, apesar do homem ser a medida de tudo, não era o objeto de infinitas medidas. Nos Jogos Olímpicos não havia a tentativa de se medir o tempo, o que teria sido difícil. E nem havia a tentativa de se medir a distância, o que teria sido fácil. Os romanos se interessavam um pouco mais pelos números, especialmente nas corridas de bigas, mas a quantificação de toda e qualquer conquista esportiva - a altura de um salto com vara à velocidade de um saque no tênis - é uma mania distintamente moderna.

A quantificação da performance fornece a base para o recorde esportivo quantificado, um conceito desconhecido antes do surgimento do esporte moderno no fim do século XVII. O que é exatamente

4 Georges Vigarello, Une Histoire culturelle du sport. Paris: Robert Laffont, 1988.

5 Rufus B. Richardson, "The New Olympian Games", Scribner's Magazine, 20. September 1896, p. 279

Movimento, Porto Alegre, v. 10, n. 3, p.9-21, setembro/dezembro de 2004 
recorde esportivo? Deixe-me citar da minha própria formulação. O recorde esportivo é um mecanismo que permite que o presente compita contra o ausente e que o vivo compita contra o morto. O recorde é um número no Livro Guinness dos Recordes e no canto superior direito da sua tela de televisão. É um estímulo a níveis inimagináveis de conquista e uma barreira física que direciona os esforços dos atletas. É uma oportunidade de exaltação, uma forma de loucura racionalizada, um símbolo da nossa civilização. Em um momento de lirismo, um atleta francês tinha esperança de que sua filha poderia "um dia recitar a litania não de nossas batalhas, mas de nossos recordes, mais belos que os trabalhos de Hércules ${ }^{\prime \prime}{ }^{6}$ Entre as características do esporte moderno, a busca por recordes talvez seja a mais significante. Para mim, a busca por recordes representa a racionalização do impulso romântico de ultrapassar os limites da possibilidade. ${ }^{7}$

Agora, de volta ao Japão: algumas formas de arco e flecha do período Tokugawa japonês exibiam essas três características racionalização, quantificação e o recorde esportivo. A racionalização apareceu mais surpreendentemente na forma do alvo moderno, que aparentemente foi inventado no Japão séculos antes do seu surgimento no Ocidente. As primeiras competições de arco e flecha provavelmente envolveram alvos vivos - como os tiros aos perus das fronteiras americanas. Finalmente, entretanto, no Japão assim como em qualquer outro lugar, os pássaros vivos foram substituídos por alvos miméticos, ou seja, alvos cujas formas imitassem as formas de pássaros e animais. Na Europa medieval, por exemplo, arqueiros atiravam no popinjay, um pássaro de madeira montado sobre um alto poste. O próximo passo no caminho da modernidade foi o de substituir o animal simulado por uma forma puramente geométrica, com um "animal" racionalizado que simbolizava - um tanto melhor que os porcos de George Orwell - a igualdade de todos os animais. Aquela forma puramente geométrica é, claro, o alvo do arco e flecha moderno. O termo inglês "Bull`s eye" (na mosca) é um lembrete residual das origens pré-modernas do alvo moderno.

Os japoneses começaram a transição dos alvos miméticos para os abstratos já no século X. Devo acrescentar, antes de prosseguir, que nem todos os alvos japoneses tomaram essas formas abstratas modernas. No inuoumono, um esporte popular no período Kamakura, trinta e seis arqueiros montados atiravam flechas sem

6 André Obey, L'Orgue du stade. Paris: Gallimard, 1924, p. 35.

7 Allen Guttmann, From Ritual to Record. New York: Columbia University Press, 1978 , p. 51-52.

Movimento, Porto Alegre, v. 10, n. 3, p. 9-21, setembro/dezembro de 2004 
ponta em cento e cinqüenta cachorros ganindo. No yabusame, arqueiros montados atiravam em alvos de madeira abstratos mas não compostos de áreas formadas por círculos concêntricos. Não há necessidade de discutir essas formas de arco e flecha. É suficiente para meus propósitos que o alvo moderno tenha surgido lado a lado com outros tipos de alvos.

O Dairi Shiki, que registra cerimônias da corte de 646 a 930 DC, contém relatos do nobre ritual de arco e flecha conhecido como jarai, que era realizado anualmente no meio do primeiro mês lunar. Parados sobre uma esteira feita de pele de cordeiro, nobres atiravam em um alvo feito de pele de veado. Um gongo soava uma vez para indicar que uma flecha havia acertado o anel de fora do alvo. O gongo soava duas vezes se a flecha se alojasse no anel do meio, e três se o anel interior - ou seja, o Bull's eye - fosse atingido. ${ }^{\prime} \mathrm{O}$ relato dado no Dairi Shiki indica claramente que os arqueiros atiravam em um alvo abstrato composto de um Bull`s eye circulado por dois círculos concêntricos.

Infelizmente, desconheço qualquer ilustração contemporânea do alvo de jirai. Minha primeira ilustração é do Kitano Tenjin-engi, um pergaminho pertencente ao Santuário Kitano de Kyoto. Ele mostra Sugawara no Michizane no pátio da corte de outro aristocrata do século IX, Miyako no Yoshika. Enquanto Yoshika e seus assistentes observavam, Michizane mira em um alvo pintado que consistia de cinco círculos concêntricos em torno de um Bull's eye. A competição de arco e flecha ocorreu em 870; o pergaminho foi feito em $1219 .{ }^{10} \mathrm{O}$ mesmo incidente aparece em outros pergaminhos, incluindo um datado de $1319 .^{.1}$

8 Este breve comentário sobre inuoumono e yabusame é retirado de Allen Guttmann and Lee Thompson, Japanese Sports: A History. Honolulu: University of Hawaii Press, 2001, p. 48-52.. Nossas principais fontes são Hayasaka Shôji, "Yabusame," Saishin supôtsu daijiten, ed. Kishino Yûzo. Tokyo: Taishûkan shoten, 1987, p. 1251-63; Obinata Katsumi, Kodai kokka to nenjû gyôji. Tokyo: Yoshikawa Bunkan, 1993. and G. Cameron Hurst, Armed Martial Arts in Japan. New Haven: Yale Univeristy, 1998.

9 Jörg Möller, Spiel und Sport am japanischen Kaiserhof. Munich: ludicium, 1993, p. 41 45; Imamura Yoshio, Nihon taiiku shi. Tokyo: Fumaidô, 1970, p. 36-37; Koyama Takashige, "Nihon kyûdô gairon," Gendai kyûdô kôza, ed. Uno Yôzaburô. Tokyo: Yûzankaku, 1982, p. 1-61.

100 pergaminho, ilustrado em Rose Hempel, Japan zur Heian-Zeit. Stuttgart: Kohlhammer, 1983, p. 161, pertence ao Santuário de Kitano.

110 pergaminho, ilustrado em Bijutsu ni miru Nihon no supôtsu. Nagoya: Tokugawa Bijutsukan, 1994), p. 10-11, pertence à Fundação Maeda

Movimento, Porto Alegre, v. 10, n. 3, p.9-21, setembro/dezembro de 2004 


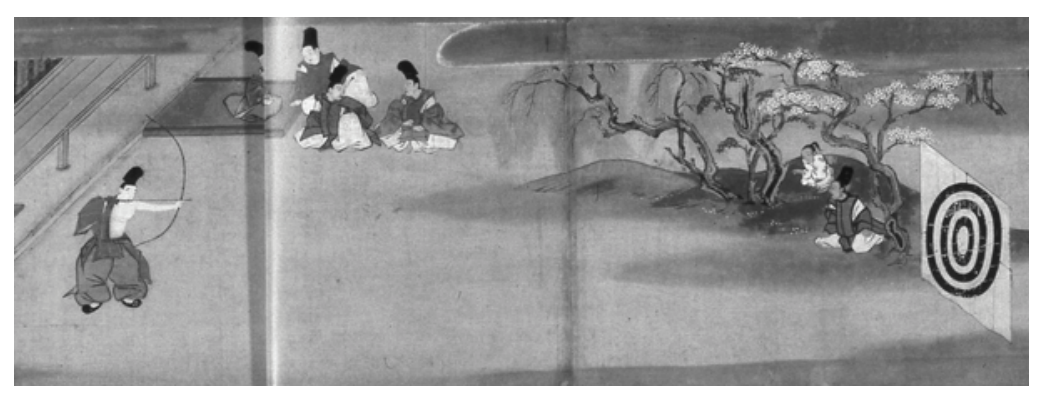

Uma terceira imagem é um detalhe de um pergaminho do século XIV descrevendo cortesãos cruzando um caminho pelas montanhas entre Kyoto e Kamekoa. Na metade superior da figura, cortesãos sobem e descem pelo caminho de Ôinosaka; na metade inferior, um menino mira em um alvo com seis anéis enquanto seu companheiro aguarda a vez. ${ }^{12}$ Existem outras incontáveis imagens de alvos semelhantes, sendo que a mais acessível é uma ilustração do século XVII sobre o clássico do século XI de Murasaki Shikibu, O Conto de Genji. Uma xilogravura de Yamamoto Shunshô, primeiramente publicada em 1650, mostra dois arqueiros montados atirando em um alvo com vários campos, preso a uma vara carregada por um homem correndo. ${ }^{13}$

Com esses exemplos japoneses em mente, quero levar em consideração os desenvolvimentos europeus. O alvo abstrato europeu parece ter aparecido primeiramente em uma ampla faixa territorial que vai da Suíça, passa pela Alemanha até o nordeste da França e Países Baixos. ${ }^{14}$ Minha primeira ilustração, feita por um artista anônimo do século XV, mostra uma competição de besta em Ghent. ${ }^{15}$

120 pergaminho, também ilustrado em Bijutsu ni miru Nihon no supôtsu, p. 10-11, pertence ao Museu Nacional de Tókio.

13 A versão de Seidensticker reedita essa ilustração na página 588 no capítulo intitulado "New Herbs."

140 alvo abstrato nunca substituiu completamente o alvo mimético. Associações de arco e flecha continuaram a atirar no popinjay, um pássaro de madeira ou metal colocado no topo de um alto poste. O popinjay era constituído de até 50 peças diferentes, cada uma das quais com um diferente valor. Arqueiros recebiam diversos prêmios por acertarem na cabeça, cauda, asa, etc. Ver Franz M. Feldhaus, "Zur Geschichte der Schießscheiben und Schießbäume," Zeitschrift für Waffenkunde , 8 (1918): 84086; Egon Hartmuth, Die Armbrust. Graz: Akademische Druck- und Verlagsanstalt, 1975); Helmut Müller, Von Schützenvögeln und Vogelschützen. (Greven: Eggenkamp, 1982).

15 De uma reprodução nos arquivos do Instituut voor Lichamelijke Opleiding, Leuven -Bélgica.

Movimento, Porto Alegre, v. 10, n. 3, p. 9-21, setembro/dezembro de 2004 


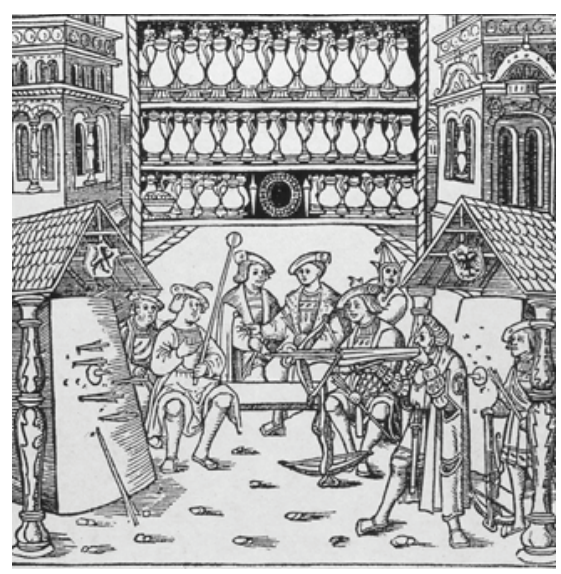

Comparado com alvos japoneses usados séculos antes este é primitivo. Parece consistir de um simples disco de papel preso no topo de uma viga. A competição parece, um tanto literalmente, ser um caso de acerte-ou-erre. O mesmo tipo de alvo aparece em uma imagem de um Schützenkönig alemão do século XVI. ${ }^{16}$

A data exata é legível: $1585 .{ }^{17}$ Meio século depois, David Teniers o Jovem desenhou um grupo de arqueiros atirando em um alvo que parece ter consistido de um pedaço de papel em forma de losango preso a uma parede de pedra. ${ }^{18}$ Não tenho a imagem dessa pintura, mas Teniers fez outra, alguns anos depois, que mos-

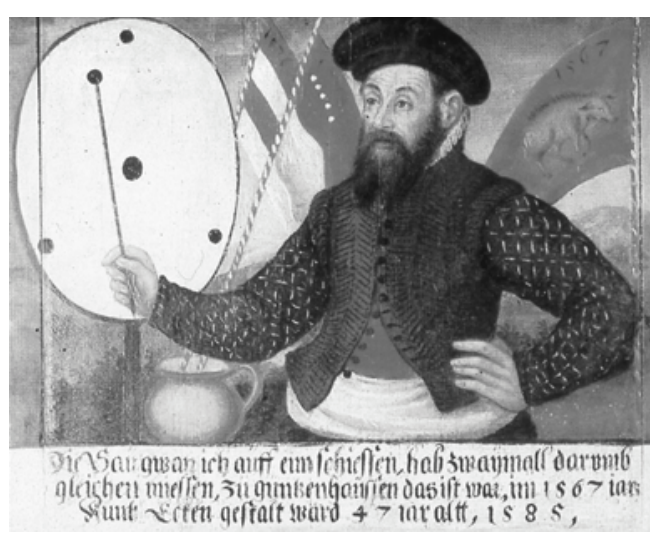
tra outro grupo de arqueiros aldeãos mirando em um círculo simples inscrito em uma folha de papel quadrada presa a uma viga. ${ }^{19}$

16 A imagem, ilustrada em Anne Braun, Historische Zie/scheiben. Leipzig: Edition Leipzig, 1981, p. 27, pertence ao the Germanisches Nationalmuseum - Nürnberg. 17 É contemporâneo a esse alvo primitivo um complicado losango dividido em 25 quadrados cujos valores eram arbitrários, com exceção dos campos dos quatro cantos que tinham o valor de $22,23,24$ e 25 pontos enquanto o campo do centro valia um ponto. A vitória era realmente uma questão de sorte.

18 Essa pintura, pertencente ao Prado em Madrid, é reproduzida em Sport in de belgische Kunst van de romeinse Tijd tot Nu, de Leon Lewille e Francine Noel, (publicado por Gemeentekredit van Beglie; local e data não fornecidos, p 100

19 De uma reprodução nos arquivos do Instituut voor Lichamelijke Opleiding, Leuven (Belgium).

Movimento, Porto Alegre, v. 10, n. 3, p.9-21, setembro/dezembro de 2004 


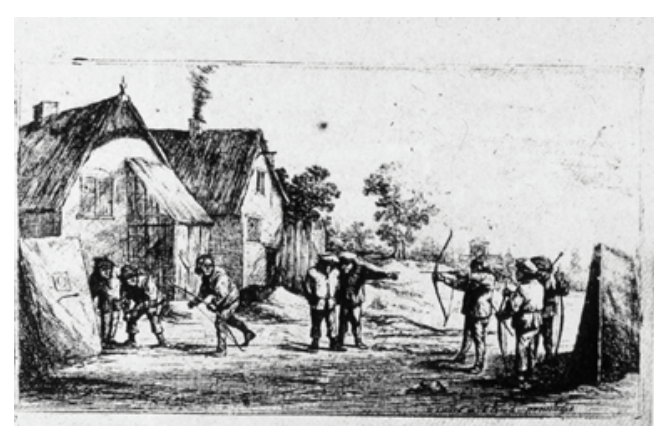

Alvos abstratos com quatro círculos concêntricos foram conhecidos na Inglaterra já em $1673 .{ }^{20} \mathrm{Em} 1754$, foi solicitado aos camareiros dos Arqueiros de Finsburg que providenciassem "um alvo ou cartolina quadrada, coberta com tecido; no centro do qual deve ser desenhado um círculo, e desse círculo quatro anéis concêntricos, que sejam visíveis e precisamente diferenciados por cores" ${ }^{21}$ No fim do século, o Príncipe de Gales decretou que o Bull’s eye e os quatro anéis concêntricos deveriam ter valores de pontos padronizados: 9, 7,5 , 3, e $1 .{ }^{22}$ Apesar da invenção de alvos cada vez mais abstratos, alvos miméticos continuaram a ser populares através do século XIX. Por vezes, os dois tipos de alvos eram combinados, como pode ser visto em um alvo misto para passatempo, do século XIX, da cidade alemã de Wissenbourg. ${ }^{23}$

Quem tomou de quem? Missionários europeus chegaram ao Japão no século XVI, mas deveria ser óbvio que os japoneses, que já atiravam em alvos abstratos por mais de trezentos anos, não foram inspirados por eles. Se eu fosse realmente precipitado em minhas especulações, poderia sugerir que foi o contrário. Talvez tenham sido os comerciantes holandeses na pequena ilha de Dejima na enseada de Nagasaki que notaram o alvo japonês e o apresentaram aos seus conterrâneos (que seriam, presumivelmente, muito estúpidos para terem inventado o alvo mo-

20 Robert Hardy, The Longbow. Cambridge: Patrick Stephens, 1976, p. 146.

21 Citado de E.G. Heath, A History of Target Archery. Newton Abbbot: David \& Charles, 1973, p. 77.

22 ibid.

23 A imagem litografada é ilustrada em Historische Zielscheiben de Braun, gravura 2.

Movimento, Porto Alegre, v. 10, n. 3, p. 9-21, setembro/dezembro de 2004 
derno por si mesmos). Muito provavelmente, o alvo moderno foi inventado independentemente pelos japoneses e - bem mais tarde - pelos europeus.

Além da racionalização, a segunda e terceira qualidades do esporte moderno são a quantificação e a busca por recordes. A evidência dessas duas características no arco e flecha pode ser vista mais claramente em uma competição, conhecida como tôshiya ("flechas limpas"). ${ }^{24}$ Registrada pela primeira vez em 1606, a competição continuou ocorrendo até 1861. Apesar de a competição ser completamente secular, realizava-se no templo Rengeô-in em Kyoto. (O templo é popularmente conhecido pelo nome de seu salão principal, o Sanjûsangendô, onde era realizada a competição.) Sentado em uma ponta de uma longa varanda no oeste do Sanjûsangendô, um único arqueiro atirava uma série de flechas que deveriam atravessar os 120 metros da varanda sem tocar o teto, pilares ou paredes (o que explica o termo "flechas limpas").

Como as flechas comuns atiradas de arcos comuns faziam um arco muito alto para o baixo corredor do Sanjûsangendô, arcos mais curtos e flechas mais leves desenvolvidos especificamente para serem usados no tôshiya. Esses arcos e flechas não podiam ser utilizados em guerras porque as flechas atingiam com muito menos impacto que aquelas lançadas pelo arco longo. Por essa razão, tradicionalistas que queriam manter o arco e flecha como uma habilidade marcial criticavam a competição como não-prática e militarmente inútil. ${ }^{25} \mathrm{~A}$ família Ogasawara, que teve um papel importante no desenvolvimento do arco e flecha ritual, se recusou a competir em tôshiya. "Tôshiya," de acordo com Cameron Hurst, "que começou como um simples teste para ver se um arqueiro podia atirar uma ou duas flechas através do longo pátio de Sanjûsangendô, foi então desenvolvida em um organizado e competitivo esporte" ${ }^{26}$

Nos 255 anos em que esse evento se realizou, um total de 823 arqueiros (contando repetentes) testou suas habilidades em tôshiya no Sanjûsangendô. O primeiro foi Asaoka Heibei, que ficou aparentemente satisfeito por acertar cinqüenta e uma flechas. Seu recorde, firmado em 1606, foi rapidamente superado. Em 1623,

24Esse relato de tôshiya é retirado de Guttman e Thompson, p. 54-56. Nossas fontes principais são: Imamura Yoshio, Nihon taiiku shi. Tokyo: Fumaidô, 1970, p. 169-81; Kohsuke Sasajima, "History of Physical Exercises and Sport in Japan," Geschichte der Leibesübungen, ed. Horst Ueberhorst, 6 vols. Berlin: Bartels \& Wernitz, 1972 1989, 6:106-13; Hurst, Armed Martial Arts. p. 136-43.

$25 /$ bid., p. 140

$26 /$ bid., p. 138.

Movimento, Porto Alegre, v. 10, n. 3, p.9-21, setembro/dezembro de 2004 
Yoshida Okura tinha aumentado o recorde para 1333 flechas. A partir de Okura, o número de flechas lançadas também passou a ser marcado (no seu caso, 2087 flechas). Esse número nos permite calcular a porcentagem de suas flechadas bem-sucedidas (63.4\%). Ao visitar Kyotodurante durante sua estada no Japão de 1690 a 1692, Engelbert Kaempfer expressou espanto pelo fato de arqueiros serem capazes de atirar "vários milhares de flechas... em um dia". ${ }^{27}$

Com o tempo a competição se tornou mais complexa, e se desenvolveu em quatro categorias principais: o ôyakazu, que durava vinte e quatro horas; o hiyakazu, que durava doze horas; a competição de mil flechas, e a competição de cem flechas. Uma proliferação de diferentes distâncias e categorias separadas para homens e meninos por fim produziu uma exibição de onze diferentes eventos. Muitos oficiais observavam a competição. Havia três juízes - um da escola do arqueiro e dois de escolas rivais. Eles seguravam bandeiras com as quais sinalizavam o êxito ou falha de cada tiro.

De 1606 a 1861, o ôyakazu foi realizado 598 vezes, mas mais da metade dessas competições - $54 \%$ para ser exato - ocorreram nos primeiros trinta anos, o que sugere que a popularidade do esporte crescia à medida que os recordes atingiam novos e intimidantes níveis. Em 255 anos, o recorde para o ôyakazu foi estabelecido 41 vezes. Uma placa memorial de 1669 marca a conquista de Hoshino Kanzaemon, que marcou 8000 sucessos em 10542 flechas. Uma segunda placa comemora o feito de Wasa Daihachirô, que ultrapassou o recorde de Kanzaemon em 1686 quando acertou 8133 em 13053 flechas. Para fazer isso, ele teve que atirar cerca de seis flechas por minuto por 24 horas, de pôr-dosol a pôr-do-sol. À direita da pintura que celebra seu recorde está o número exato de flechas lançadas (em números japoneses).

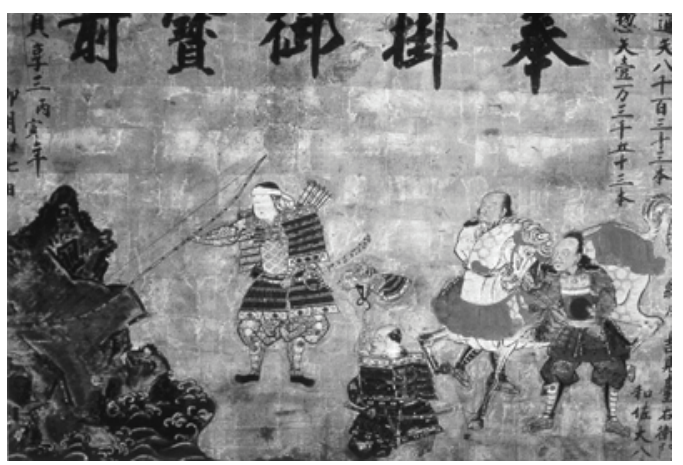

27 Kaempfer: citado em John M. Rogers, "Arts of War in Time of Peace," Monumenta Nipponica, 45:3, Outono de 1990, p. 257.

Movimento, Porto Alegre, v. 10, n. 3, p. 9-21, setembro/dezembro de 2004 
A competição de Kyoto se tornou conhecida para arqueiros em todo o Japão, nem todos capazes de viajar até Kyoto para competir Para acomodar os arqueiros hábeis em Edo, um Sanjûsangendô foi construído naquela cidade em 1642. Lá, entre 1645 e 1852, 544 arqueiros (contando repetentes) testaram suas habilidades no tôshiya em vinte e um diferentes eventos em vários tempos, distâncias, limite de flechas e de idade. As mais espetaculares conquistas foram aquelas do lendário Kokura Gishichi. Na sua primeira participação, aos 11 anos de idade, em 1827, ele errou apenas cinco dos seus mil tiros na distância de "meio corredor".

Edo não foi o único lugar onde uma réplica do Sanjûsangendô foi construída. Os clãs Sendai e Shônai, por exemplo, construíram seus próprios quase autênticos Sanjûsangendô nos seus domínios e realizavam suas próprias competições de tôshiya. Outros domínios realizaram competições similares em instalações já existentes. Os Aizu, por exemplo, usaram um depósito com uma longa varanda localizado no terreno do seu castelo, hoje a residência oficial dos administradores de Fukushima. ${ }^{28}$

Dois historiadores, Sasajima Kôsuke e Homma Shuku, sustentam que as placas colocadas no templo para celebrar os feitos de Hoshino Kanzaemon e Wasa Daihachirô são provas e que os japoneses do século XVII entendiam o conceito de recorde esportivo quantificado. A evidência parece apoiar sua causa. Outra colocação parece menos convincente. De acordo com Sasajima, o ôyakazu "saiu de voga" porque "as pessoas achavam difícil quebrar o recorde"..$^{29}$ Isso pode ter sido o caso, mas não acredito. Afinal de contas, a competição continuou por cento e cinqüenta e seis anos depois que Daihachirô estabeleceu o recorde. Qualquer que tenha sido a razão para a eventual perda de popularidade do esporte, as conquistas quantificadas do tôshiya foram completamente esquecidas enquanto os japoneses e seus admiradores estrangeiros se tornaram fascinados pelo charme místico do Zen na arte do arco e flecha.

Deixe-me resumir e concluir. Séculos antes do arco e flecha moderno ter surgido como um esporte europeu, uma forma de arco e flecha japonês envolvia o uso de alvos abstratos. No século XVII, outra forma de arco e flecha japonês, uma que não utilizava os alvos de anéis concêntricos com vários campos, enfatizava a quantificação e a busca de recordes. Essa forma de arco e flecha surgiu no Japão precisamente no mesmo momento em que o esporte europeu começou a manifestar uma mania similar por números e recorde esportivo

28 Imamura, Nihon Taiiku shi, p. 169-181

29 Sasajima, p. 106-113.

Movimento, Porto Alegre, v. 10, n. 3, p.9-21, setembro/dezembro de 2004 
quantificado. Se todas as três dessas características do esporte moderno - racionalização, quantificação e a busca de recordes - estavam presentes no esporte japonês dois séculos antes dos modernizadores do período Meiji começarem a emprestar do Ocidente, então a surpreendentemente rápida aceitação do beisebol e outros esportes modernos pelos japoneses é um tanto mais fácil de se entender. Assim a modernização japonesa é um tanto mais fácil de ser entendida, afinal, as sementes da modernidade já estavam presentes em 1853 quando os indesejáveis navios do Comodoro Mathew Perry ancoraram em águas japonesas.

Targeting modernity
Archery and the modernization of Japan
Abstract: The text analyses the modernization of the
Japanese society regarding the swift acceptance of
modern sports from Europe and North America.
Focusing the practice of the Japanese archery (kyûjutsu)
and identifying it as a non-European activity, the main
argument is that the quick acceptance of modern sports
by the Japanese society can be better understood when
we verify that some of the main characteristics of this
sport (rationalization, quantification and the quest for
records), were already present in the Japanese society,
before the period of reformation of the country. Seeking
to show how the characteristics of modern sports are
identifiable in the practice of Japanese archery, it's
concluded that, being the seeds of modernity present in
Japan before the modernization process itself, it's easier
to understand this historical event.
Keywords: History, Culture, Sport, Modernity.

Movimento, Porto Alegre, v. 10, n. 3, p. 9-21, setembro/dezembro de 2004 


\begin{abstract}
Visando la modernidad
Arco y flecha y la modernización del Japón

Resumen: el texto analiza la modernización de la sociedad japonesa en lo que se refriere a la rápida aceptación de deportes modernos oriundos de la Europa y de la América del Norte. Focalizando la práctica del arco y la flecha japonés (kyûjutsu) e identificándolo como una actividad no europea, el argumento central es el de que la rápida aceptación de los deportes modernos por la sociedad japonesa puede ser mejor entendida cuando verificamos que algunas de las principales características de este deporte (la racionalización, la cuantificación y la búsqueda del récord), ya estaban presentes en la sociedad japonesa, antes del periodo de la reforma de aquel país. Buscando mostrar como las características del deporte moderno son identificables en la práctica del arco y flecha japonés, se conclue que, estando las semillas de la modernidad presentes en el japón antes del propio proceso de modernización, se torna más fácil la comprensión de este acontecimiento histórico.

Palabras clave: Historia, Cultura, Deporte, Modernidad.
\end{abstract}

